\title{
Diagnostic performance of endoscopic ultrasound-guided fine-needle aspiration for cystic and non-cystic pancreatic neuroendocrine tumors
}

\section{다)(1) $\odot(9)$}

Authors

Amaninder Jeet Singh Dhaliwal ${ }^{1}$, Jonathan R. Strosberg², Barbara A. Centeno ${ }^{2}$, Shivakumar Vignesh ${ }^{3}$

Institutions

1 Department of Gastroenterology and Hepatology, University of Nebraska Medical Center, Omaha, Nebraska, United States

2 H. Lee Moffitt Cancer Center and Research Institute and University of South Florida College of Medicine, Tampa, Florida, United States

3 Division of Gastroenterology and Hepatology, SUNY Health Sciences Center at Brooklyn, Brooklyn, New York, United States

submitted 17.7.2018

accepted after revision 22.2.2019

\author{
Bibliography \\ DOI https://doi.org/10.1055/a-0915-9496 | \\ Endoscopy International Open 2019; 07: E854-E859 \\ (c) Georg Thieme Verlag KG Stuttgart · New York \\ elSSN 2196-9736
}

Corresponding author

Amaninder Jeet Singh Dhaliwal MD, Department of

Gastroenterology and Hepatology, University of Nebraska

Medical Center, 982000 Nebraska Medical Center,

Omaha, NE 68198-2000

Fax: +1-402-559-9004

a.dhaliwal@unmc.edu

dramaninderdhaliwal@gmail.com

\section{ABSTRACT}

Background and study aims Pancreatic neuroendocrine tumors (P-NENs) are rare tumors with malignant potential. Endoscopic ultrasound-guided fine-needle aspiration (EUSFNA) has been shown to be superior to other imaging methods in preoperative localization and diagnosis of P-NENs. The objective of this study was to describe the EUS features of non-metastatic cystic and non-cystic P-NENs seen at a referral center and to evaluate the performance of EUS-FNA in diagnosis of P-NENs.

Patients and methods All patients with histologically confirmed, non-metastatic P-NENs, which underwent EUSFNA prior to surgical resection at the Moffitt Cancer Center between Jan 2005 and Dec 2012 were included. Clinical, endoscopic and pathologic information was abstracted from electronic medical records.

Results Thirty-nine patients, all with non-functional PNENs, were included in this study. Thirteen tumors were cystic and 26 were solid. Among the cystic tumors, 50\% were partly cystic and partly solid, and $50 \%$ were fully cystic. The cystic tumors were more commonly seen at the body/ tail, and the solid tumors were more uniformly distributed. Fluid could be aspirated from $50 \%$ of the cystic tumors, all with a carcinoembryonic antigen level $<192 \mathrm{ng} / \mathrm{mL}$. With surgical pathology as the gold standard, overall sensitivity of EUS-FNA in diagnosing cystic tumors was $62.5 \%$, and for solid tumors, $95 \%(P<0.03)$.

Conclusions EUS-FNA is much more sensitive in diagnosing solid P-NENs than cystic PNETs. Our results indicate that EUS-FNA may have higher sensitivity for diagnosis of cystic P-NENs than the reported sensitivity of EUS-FNA for all pancreatic cystic tumors.

\section{Introduction}

Neuroendocrine tumors (NENs) describe a heterogeneous group of tumors with a wide range of morphologic, functional, and behavioral characteristics. Pancreatic neuroendocrine tumors (P-NENs) are subset of NENs and represent a small percentage of all pancreatic tumors (1.3\%) but their incidence is rising
[1]. Incidence of PNETs may be significantly underestimated in tumor registries, including the Surveillance, Epidemiology and End Results (SEER) program, which include only malignant neoplasms. Most P-NENs are solitary, well-demarcated and well-differentiated neoplasms. Multifocal tumors are rare and should always raise suspicion of multiple endocrine neoplasia 1 (MEN1) or von Hippel Lindau syndrome (VHL). 
Based on WHO classification (2017), P-NENs have been classified as: (1) well-differentiated PanNENs: pancreatic neuroendocrine tumors (PanNETs); (2) poorly differentiated PanNENs: pancreatic neuroendocrine carcinomas (PanNECs); or (3) mixed neuroendocrine: non-endocrine neoplasm [2]. Most P-NENs are solid tumors, although cystic variants have been described as well, which can be misdiagnosed as mucinous or serous cystadenomas of the pancreas [3].

When possible, surgical resection of localized P-NENs is recommended; hence, preoperative localization is essential. Based on several studies, computed tomography (CT) has reported sensitivity of $64 \%$ to $82 \%$ in diagnosis of P-NENs. Their sensitivity decreases further when lesion size is $<2 \mathrm{~cm}[4,5]$. Somatostatin receptor scintigraphy (SRS) is useful in non-insulinoma P-NENs with an overall reported sensitivity of $58 \%$ to $86 \%$, whereas in insulinomas, its use is limited because of the lower density of somatostatin receptors [6,7]. (68) Ga-DOTATATE positron emission tomography (PET/CT) is a new modality for replacing octreotide scan for small PNETs as long as they express somatostatin receptors. Sadowski et al. 2016 showed that (68) Ga-DOTATATE PET/CT detected P-NENs in $65.2 \%$ of patients with negative biochemical testing but positive carcinoid symptoms. In the $65.2 \%$ of patients with detected lesions, $40 \%$ of the lesions were not even detected by $\mathrm{CT} /$ magnetic resonance imaging (MRI) and PET imaging studies [8]. EUS has been shown to be superior to other imaging methods in preoperative imaging and localization of P-NENs [4, 9]. EUS-FNA was first described for cytological confirmation of P-NENs in 2002 [9]. Several additional retrospective series describing the endosonographic features and usefulness of FNA in diagnosis on PNENs have been published $[2,10,11]$.

However, data are limited on diagnostic performance of EUS-FNA when comparing solid and cystic P-NENs. The sensitivity of EUS FNA assessed against a surgical gold standard is reported in few studies. To our knowledge, the largest study addressing this issue was published in 2010 [12], including 68 patients with P-NENs who underwent EUS-FNA for diagnosis, with a sensitivity of $87 \%$. There is also a relative dearth of studies describing chemical analyses of fluid aspirated from cystic P-NENs via EUS-FNA. Therefore, we performed a retrospective singlecenter study to assess sensitivity of EUS-FNA in diagnosing cystic and non-cystic P-NENs, and also to describe the EUS features of non-metastatic, cystic and solid P-NENs.

\section{Patients and methods}

We conducted a retrospective chart review of all cases of PNENs between January 2005 and December 2012 seen at the Moffitt Cancer Center. The study was conducted with the approval of the Institutional Review Board (IRB\#00001124). A database of all the P-NENs seen at our institution during that interval was used as the primary source. From this database, we identified all cases of patients with histologically confirmed, non-metastatic P-NENs who underwent EUS prior to surgical resection. This time frame was chosen to ensure that the results reflected the outcome expected from the current state of EUS technology.
Electronic medical records of these patients were reviewed. The following clinical information was recorded: age, sex, presence of symptoms (i.e. weight loss, abdominal pain, flushing, diarrhea, jaundice, hypoglycemic episodes), and if presence of a P-NEN was suspected based on the symptoms, or pre-EUS radiological imaging.

\section{EUS examination}

All procedures were performed by three experienced endosonographers after informed consent was obtained. The endosonographers had between 5 and 10 years' experience and had completed 3000 to 7000 EUS procedures. EUS was performed with an Olympus GF-UC140PAL5 curvilinear echo endoscope (Olympus America, Inc, Center Valley, Pennsylvania, United States). A cytopathologist was usually available on-site for preliminary interpretations. Cook Medical Echo Tip Ultra $25 \mathrm{G}$ or $22 \mathrm{G}$ needles were used for FNA and 22G needle used for fluid aspiration in cystic tumors. The suction technique was preferentially used for EUS-FNA and fanning technique only in the case of solid lesions. Per policy, if EUS-FNA was performed on a cystic lesion, the patient received one dose of intravenous antibiotics (ampicillin/sulbactam or ciprofloxacin) followed by 3 to 7 days of oral antibiotics (amoxicillin/clavulinic acid or ciprofloxacin). Details of the EUS-FNA examinations were abstracted from the dictated reports, available from the electronic medical records.

\section{Cytologic examination}

Cytomorphological diagnosis of a P-NEN was considered based on the appearance of monomorphic cells with an eccentrically located, moderately large, round to oval nucleus with finely stippled and uniformly dispersed chromatin ( $\triangleright$ Fig.1a, $>$ Fig. 1b, > Fig. 2a, > Fig. 2b). Immunohistochemical staining of chromogranin and synaptophysin was performed at the discretion of the pathologist ( $\mathbf{F i g . 2 c} \mathbf{2}$ Fig. $\mathbf{2 d}$ ). Each cytopathology and surgical pathology ( $\triangleright$ Fig. $\mathbf{3 a}$, $\triangleright$ Fig. $\mathbf{3 b}$ ) specimen was reviewed by one of three experienced gastrointestinal pathologists. If

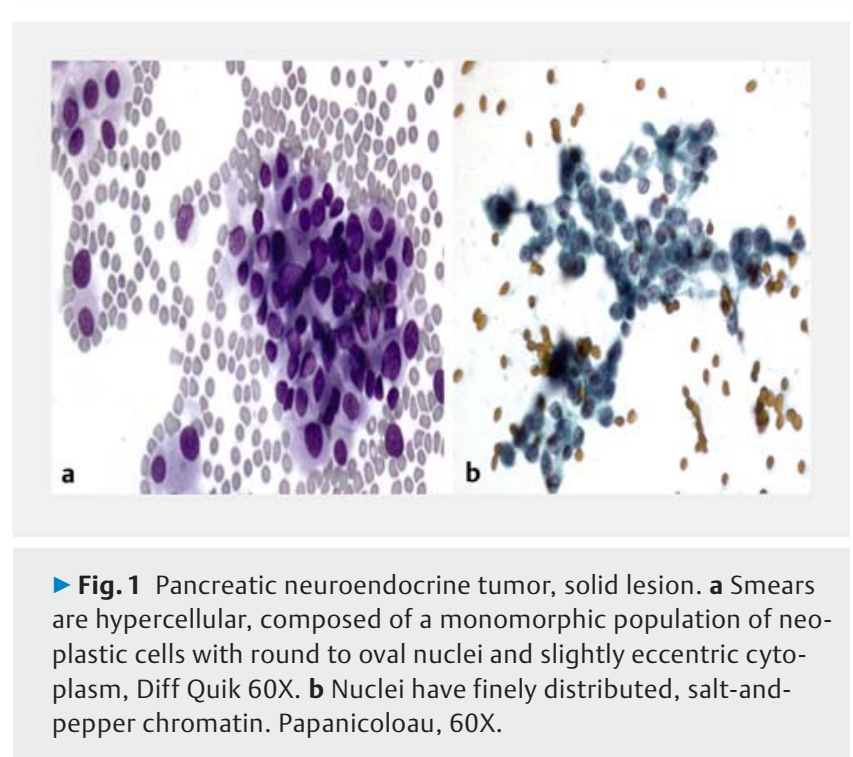



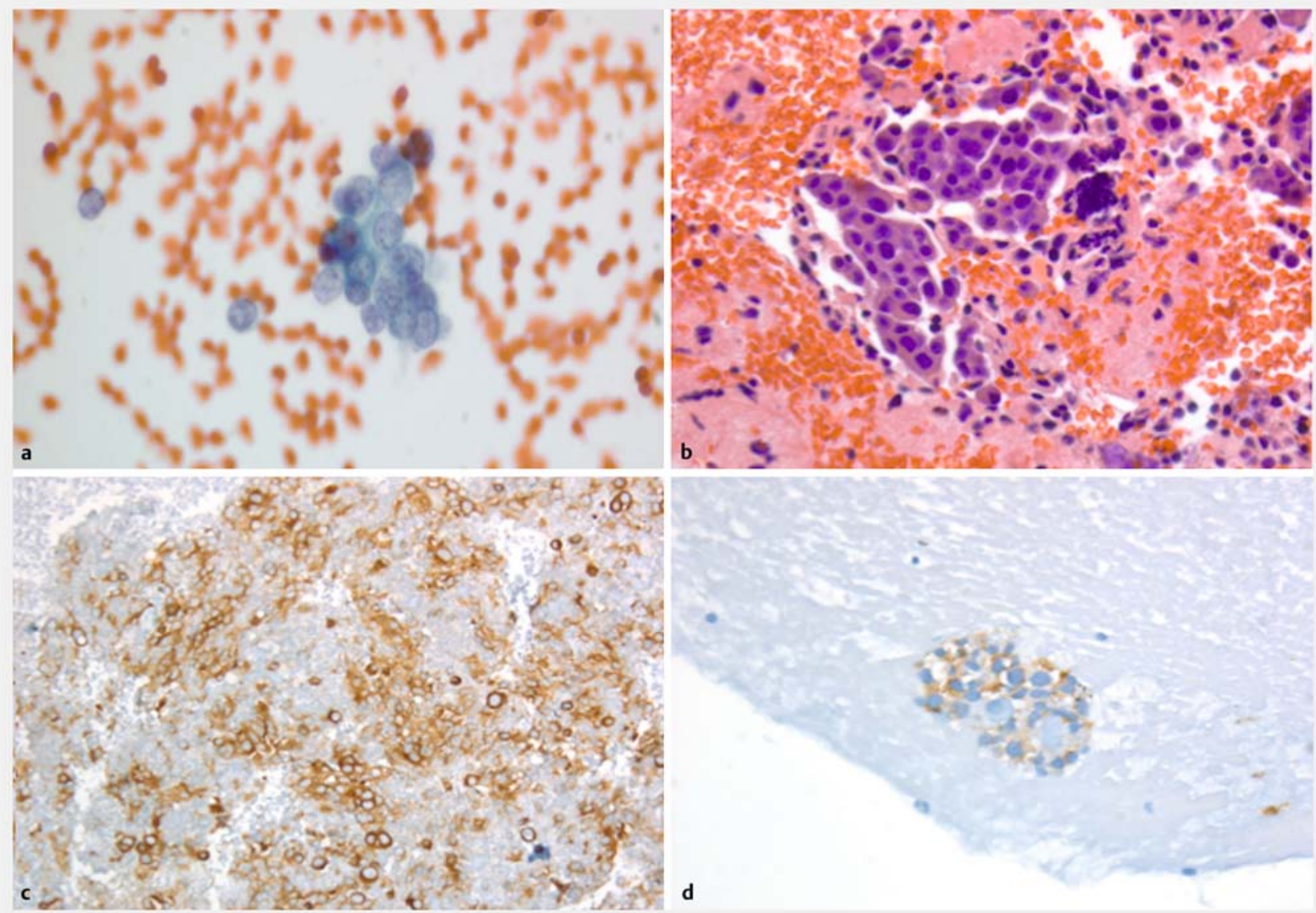

- Fig. 2 Pancreatic neuroendocrine tumor, cystic lesion. a Small groups of monomorphic cells and single cells with scant, amphophilic cystoplasm are identified on the cytospin. Nuclei are round to oval and the chromatin is finely distributed, with a salt and pepper pattern. Papanicolaou, 60X. b The cellblock shows single cells. Hematoxylin and eosin, 40X. $\mathbf{c}$ The neoplastic cells express synaptophysin and $\mathbf{d}$ chromogranin. Peroxiadase, 40X.

fluid was aspirated, fluid analysis included cytospin analysis, amylase and carcinoembryonic antigen (CEA) levels.

\section{Statistical analysis}

Surgical pathology was used as gold standard for EUS-FNA sensitivity analysis. Stata 10.0 software was used for statistical analysis. For analysis purposes, continuous variables were expressed as means and standard deviations, and dichotomous variables were expressed as simple proportions with or without $95 \%$ confidence intervals $(\mathrm{Cl})$. Continuous variable associations were assessed with an unpaired $t$ test. The association between categorical variables and malignancy was assessed with the Fisher exact test. $P<.05$ was considered significant.

\section{Results}

\section{Patient population}

Thirty-nine patients met our inclusion criteria, 26 with solid PNENs and 13 with cystic P-NENs. There was a higher preponderance of females in the cystic P-NEN group ( $\bullet$ Table 1 ).

\section{Clinical features}

The majority of patients in our study had either no symptoms or non-specific symptoms ( $\triangleright$ Table 1 ). Most of the patients had some form of imaging performed prior to EUS, CT being the most common modality. All the patients in the solid P-NEN group had an abnormal imaging result on pre-EUS imaging, with a solid lesion being seen in $96 \%$ of cases. Within the cystic P-NEN group, $84.6 \%$ of cases had an abnormal imaging result. A cystic component to the lesion was picked up in only $53.8 \%$ of cases ( $\vee$ Table $\mathbf{1}$ )

\section{Endosonographic features}

Cystic tumors were more commonly seen in the body and tail of the pancreas whereas solid tumors were uniformly distributed throughout the pancreas $(P<0.02)$. There was no significant difference in size between cystic and solid tumors. The main pancreatic duct and rest of the pancreatic parenchyma were normal-appearing in a majority of the cases $(91.7 \%$ and $94.1 \%$, respectively). The majority of the solid P-NENs were well demarcated (66.7\%). The echotexture of the solid P-NENs was mostly hypoechoic or heterogeneous. The cystic component 

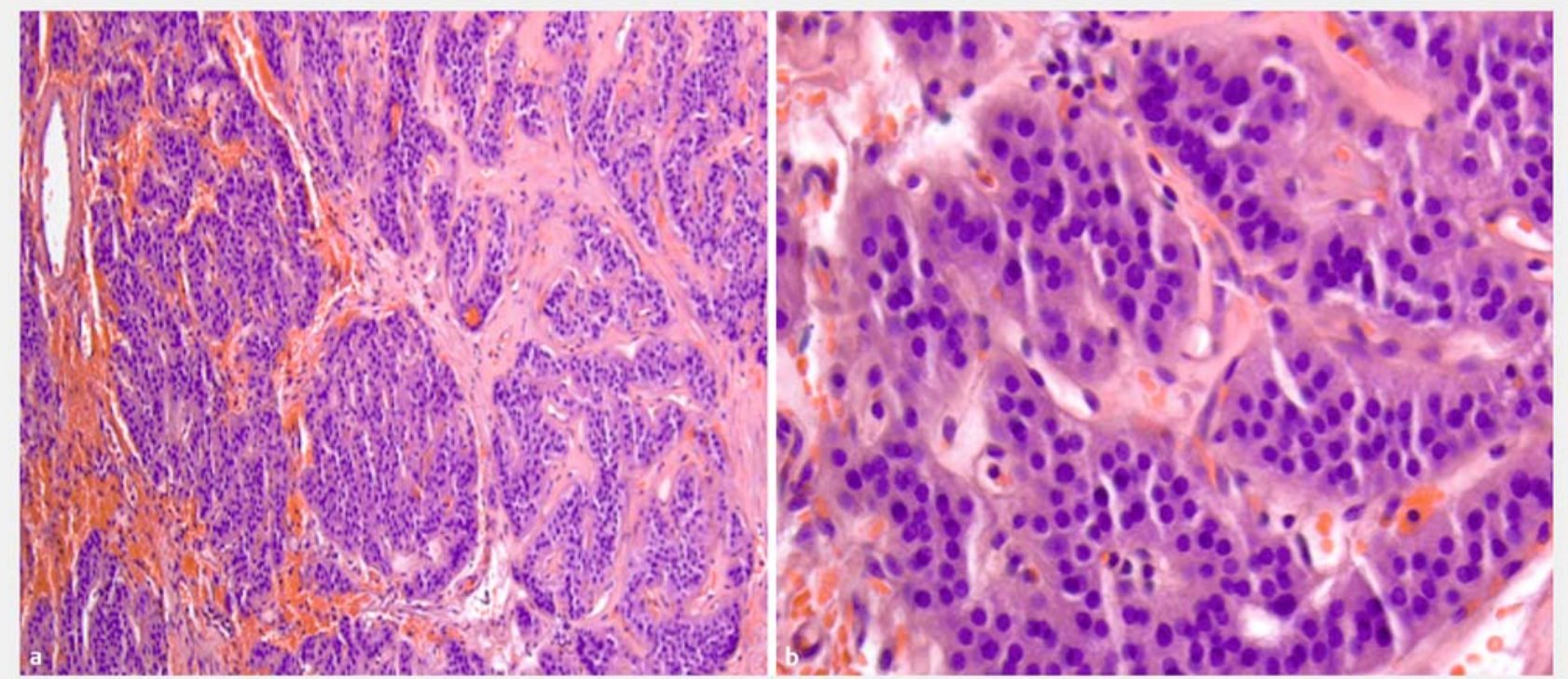

- Fig. 3 Pancreatic neuroendocrine tumor, resection. a Low-power image shows monomorphic neoplastic cells arranged in a trabecular and gyriform pattern surrounded by vascular, fibrous stroma. Hemaotxylin and eosin, 10X. b Neoplastic cells have round, uniform nuclei with salt and pepper chromatin and fine granular, eosinophilic cytoplasm. Hemaotxylin and eosin, 40X.

- Table 1 Patient demographics and clinical characteristics.

\begin{tabular}{|c|c|c|c|}
\hline & $\begin{array}{l}\text { Solid P-NEN } \\
\mathrm{N}=\mathbf{2 6}\end{array}$ & $\begin{array}{l}\text { Cystic P-NEN } \\
N=13\end{array}$ & $P$ \\
\hline Age mean (SD) & $56.4(13.1)$ & $63.8(10.5)$ & 0.1 \\
\hline Sex, \% & $\begin{array}{l}M, 30.8 \\
F, 69.2\end{array}$ & $\begin{array}{l}M, 61.5 \\
F, 38.5\end{array}$ & 0.06 \\
\hline Symptoms, n (\%) & $\begin{array}{l}\text { Asymptomatic 9/26(34.6) } \\
\text { Nonspecific Sx } 15 / 26(61.5) \\
\text { Specific Sx 2/26 (7.6) }\end{array}$ & $\begin{array}{l}\text { Asymptomatic 8/13 (61.5) } \\
\text { Nonspecific Sx 5/13(38.5) } \\
\text { Specific Sx 0/13 }\end{array}$ & 0.2 \\
\hline Pre-EUS radiology, n (\%) & $\begin{array}{l}\text { CT } 23 / 26(92) \\
\text { MRI } 1 / 26(4) \\
\text { US } 1 / 26(4) \\
\text { None } 1 / 26\end{array}$ & $\begin{array}{l}\text { CT 12/13 (92.3) } \\
\text { MRI 1/13 (7.8) }\end{array}$ & 0.7 \\
\hline Radiological* diagnosis, n (\%) & $\begin{array}{l}\text { No Lesion 0/25 } \\
\text { Cystic lesion 0/25 } \\
\text { Solid Lesion } 24 / 25 \text { (96) } \\
\text { Solid/Cystic lesion } \\
0 / 25 \\
\text { Fullness } 1 / 25 \text { (4) }\end{array}$ & $\begin{array}{l}\text { No Lesion } 2 / 13(15.4) \\
\text { Cystic lesion } 7 / 13(53.8) \\
\text { Solid Lesion } 2 / 13(15.4) \\
\text { Solid/Cystic lesion } \\
2 / 13(15.4) \\
\text { Fullness } 0 / 13\end{array}$ & NA \\
\hline
\end{tabular}

of the cystic P-NENs was most commonly anechoic. Among the cystic tumors, $50 \%$ were partly cystic and partly solid, and $50 \%$ were fully cystic. Vascular involvement was seen in only one solid P-NEN, and in none of the cystic P-NENs ( $\triangleright$ Table 2).

\section{FNA results}

FNA was performed for 23 of 26 of solid P-NENs ( $\bullet$ Table 3 ). Most of the operators used a $25 \mathrm{G}$ needle. A diagnosis could be obtained in two to five passes in the majority of cases, yielding an overall sensitivity of 95\% (19/20) for EUS-FNA for solid PNENs when compared with surgical pathology. Among the cystic P-NENs, FNA of the solid component was performed in five 
- Table 2 Endosonographic features of P-NENs.

\begin{tabular}{|c|c|c|c|}
\hline & $\begin{array}{l}\text { Solid P-NEN } \\
N=26\end{array}$ & $\begin{array}{l}\text { Cystic P-NEN } \\
N=13\end{array}$ & $P$ \\
\hline Location, n (\%) & $\begin{array}{l}\text { Head } 6 / 26(23.1) \\
\text { Neck } 5 / 26(19.2) \\
\text { Body } 5 / 26(19.2) \\
\text { Tail } 4 / 26(15.4) \\
\text { Uncinate } 6 / 26(23.1)\end{array}$ & $\begin{array}{l}\text { Head } 2 / 13(15.4) \\
\text { Neck } 1 / 13(7.7) \\
\text { Body } 3 / 13(23.1) \\
\text { Tail } 7 / 13(53.8) \\
\text { Uncinate } 0 / 11\end{array}$ & 0.1 \\
\hline $\begin{array}{l}\text { Size } \\
\text { Mean (SD) }\end{array}$ & $23(11.7) \mathrm{mm}$ & $22.3(12.1) \mathrm{mm}$ & 0.7 \\
\hline Margins $^{1}, \mathrm{n}(\%)$ & $\begin{array}{l}\text { Well-demarcated } 17 / 24(70.8) \\
\text { Poorly demarcated } 7 / 24(29.16)\end{array}$ & NA & NA \\
\hline Echotexture $^{2}, \mathrm{n}(\%)$ & $\begin{array}{l}\text { Hypoechoic } 15 / 26(57.7) \\
\text { Hyperechoic } 1 / 26(3.9) \\
\text { Heterogeneous } 8 / 26(30 / 8) \\
\text { Isoechoic } 1 / 26(3.9) \\
\text { Hypo with Anechoic Features } 1 / 26(3.9)\end{array}$ & $\begin{array}{l}\text { Anechoic } 10 / 13(76.9) \\
\text { Anechoic with debris } 1 / 13(7.7) \\
\text { Hypoechoic } 2 / 13(15.4) \\
\text { Septations } 1 / 13(7.7) \\
\text { Mural Nodules } 2 / 13(15.4)\end{array}$ & NA \\
\hline PD Dilation & $0 / 26$ & $0 / 13$ & NA \\
\hline Extra lesional parenchyma & Normal-appearing 26/26 & Normal-appearing 13/13 & NA \\
\hline Vascular involvement & $1 / 26$ & $0 / 13$ & NA \\
\hline
\end{tabular}

- Table 3 Fine-needle aspiration results of solid P-NENs (FNA performed on 23/26 solid P-NENs).

\begin{tabular}{l|l|}
\hline Needle used, $\mathrm{n}(\%)$ & $19 \mathrm{G}-1 / 23(4.3)$ \\
& $\begin{array}{l}22 \mathrm{G}-4 / 23(17.4) \\
25 G-18 / 23(78.3)\end{array}$ \\
\hline Passes made, $\mathrm{n}(\%)$ & $\begin{array}{l}2-5 \text { passes }-17 / 23(73.9) \\
6-9 \text { passes - 6/23 (26.1) }\end{array}$ \\
\hline Cytology results, n (\%) & $\begin{array}{l}\text { P-NEN 22/23 (95.6) } \\
\text { Non-Diagnostic 1/23 (4.3) }\end{array}$ \\
\hline $\begin{array}{l}\text { Overall sensitivity of EUS-FNA com- } \\
\text { pared with surgical pathology*, n (\%) }\end{array}$ & $19 / 20$ (95) \\
\hline $\begin{array}{l}\text { P-NEN, pancreatic neuroendocrine neoplasm; FNA, fine-needle aspiration; } \\
\text { EUS, endoscopic ultrasound } \\
\text { * Surgical pathology available for 20 of 23 solid P-NEN patients, of whom } \\
\text { only 19 were confirmed solid P-NENs. }\end{array}$
\end{tabular}

of 13 cases, and cystic component in nine of 13 cases, with a $25 \mathrm{G}$ needle and a $22 \mathrm{G}$ needle, respectively. One case had both solid and cystic component biopsied ( $>$ Table 4). Cytological diagnosis of P-NENs was obtained from three of five cases (60\%) from the solid component, and six of nine cases (66.7\%) from the cystic component. Surgical pathology was available for eight of 13 cystic P-NEN cases only. Of them, only five were confirmed cystic P-NENs, yielding an overall sensitivity of EUS FNA for cystic P-NENs of $62.5 \%$ (5/8). Fluid could be aspirated from $50 \%$ of the cystic tumors, all with a CEA level $<192 \mathrm{ng} / \mathrm{mL}$, and a normal amylase level. Mean amount of fluid aspirated was $4.9 \mathrm{cc}$. No adverse events were encountered in our study population.
Table 4 Fine-needle aspiration results of cystic P-NENs $(N=13)$.

\begin{tabular}{|c|c|}
\hline FNA of solid component & $5 / 13$ \\
\hline FNA of systic component ${ }^{1}$ & $9 / 13$ \\
\hline Needle used & $\begin{array}{l}\text { Solid-25G } \\
\text { Cystic-22 G }\end{array}$ \\
\hline Passes done & $\begin{array}{l}\text { Solid }-3 \text { to } 7 \\
\text { Cystic }-1 \text { to } 2\end{array}$ \\
\hline Cytology solid, n (\%) & $\begin{array}{l}\text { P-NEN-3/5 (60) } \\
\text { Carcinoma - } 1 / 5(20) \\
\text { Non-diagnostic } 1 / 5(20)\end{array}$ \\
\hline Cytology cystic, n (\%) & $\begin{array}{l}\text { P-NEN 6/9 (66.7) } \\
\text { MCN 1/9 (11.1) } \\
\text { No diagnostic 2/9 (22.2) }\end{array}$ \\
\hline Fluid amount & $4.9 \pm 3.6 c c$ \\
\hline Fluid CEA $(n=4)$ & $\begin{array}{l}6.6 \pm 12.1 \\
<192 \text { in call cases }\end{array}$ \\
\hline Fluid amylase $(n=4)$ & $\begin{array}{l}203 \pm 180 \\
\text { WNL in all cases }\end{array}$ \\
\hline $\begin{array}{l}\text { Overall sensitivity of EUS-FNA compar- } \\
\text { ed with surgical pathology }{ }^{2}, \mathrm{n}(\%)\end{array}$ & $5 / 8(62.5)$ \\
\hline \multicolumn{2}{|c|}{$\begin{array}{l}\text { P-NEN, pancreatic neuroendocrine neoplasm; MCN, mucinous cystic neo- } \\
\text { plasm; FNA, fine-needle aspiration; CEA, carcinoembryonic antigen; WNL, } \\
\text { within normal limits } \\
1 \text { One case had both solid and cystic component sampled } \\
{ }^{2} \text { Surgical pathology was available for eight of } 13 \text { cystic P-NEN cases only, of } \\
\text { which only five were confirmed cystic P-NENs. }\end{array}$} \\
\hline
\end{tabular}




\section{Discussion}

Diagnosis of P-NENs is difficult with standard imaging techniques $[4,10,12,13]$. EUS- FNA has emerged as a promising and highly accurate tool in imaging, diagnosing, and staging P-NENs. A majority of the P-NENs in most of the published series have been non-functioning P-NENs, which matches our experience. The EUS features of solid P-NENs were consistent with other major series [9], with most of them being well demarcated, with a normal-appearing pancreas, and a majority presenting without vascular involvement. The echotexture of the solid P-NENs was mostly hypoechoic or heterogeneous. In our study, the solid P-NENs had a relatively uniform distribution in the pancreatic head versus body or tail region, which is consistent with other series.

The EUS features of cystic PNETs have not been very well characterized in the literature. The largest series on cystic PNENs had 50 patients [14]. All of them were non-functioning P-NENs, which is again similar to other series. The majority of the cystic P-NENs in our series were in the body or tail region, and their cystic component was anechoic with no vascular involvement. Based on these EUS features, the cystic P-NENs could be mistaken for mucinous cystadenomas or side branch IPMN of the tail region.

EUS-FNA again proved to be highly sensitive for diagnosing solid P-NENs, and it could establish the diagnosis in 22 of 23 cases (95\%), which is consistent with other series $[9,12]$. For cystic P-NENs, it could establish diagnosis in six of nine cases $(66.7 \%)$, and it required FNA of both the solid and cystic components. This is the first assessment of the sensitivity of EUSFNA for cystic P-NENs, to the best of our knowledge. Another important, and new piece of information is that CEA and amylase levels in the fluid aspirated from these cystic tumors was normal in all cases, helping to distinguish them from mucinous cystic neoplasms. Serous cystadenomas are the only other cystic neoplasms of the pancreas, which have similar fluid analysis findings,

\section{Conclusion}

In summary, we present experience with EUS-FNA at a large National Cancer Institute-designated cancer center for diagnosing solid and cystic P-NENs. Sensitivity of EUS-FNA for solid PNETs is excellent, but is lower for cystic P-NENs. Often FNA of the solid and cystic P-NENs is required to establish the diagnosis. We recommend that cystic P-NENs be considered in differential diagnosis of cystic neoplasms of the pancreas, especially if the CEA level is below the cutoff of $192 \mathrm{ng} / \mathrm{mL}$.
Competing interests

None

References

[1] Ehehalt F, Saeger HD, Schmidt CM et al. Neuroendocrine tumors of the pancreas. Oncologist 2009; 14: 456-467

[2] Scoazec JY, Couvelard A, Reseau T et al. Classification of pancreatic neuroendocrine tumors: Changes made in 2017 WHO classification of tumors of endocrine organs and perspectives for the future. Ann Pathol 2017; 37: 444-456

[3] Charfi S, Marcy M, Bories E et al. Cystic pancreatic endocrine tumors: an endoscopic ultrasound-guided fine-needle aspiration biopsy study with histologic correlation. Cancer 2009; 117: $203-210$

[4] Patel KK, Kim MK et al. Neuroendocrine tumors of the pancreas: endoscopic diagnosis. Curr Opin Gastroenterol 2008; 24: 638-642

[5] Khashab MA, Yong E, Lennon AM et al. EUS is still superior to multidetector computerized tomography for detection of pancreatic neuroendocrine tumors. Gastrointest Endosc 2011; 73: 691-696

[6] Zimmer T, Stolzel U, Bader M et al. Endoscopic ultrasonography and somatostatin receptor scintigraphy in the preoperative localisation of insulinomas and gastrinomas. Gut 1996; 39: $562-568$

[7] Zimmer T, Ziegler K, Bader M et al. Localisation of neuroendocrine tumours of the upper gastrointestinal tract. Gut 1994; 35: 471-475

[8] Sadowski SM, Neychev V, Millo C et al. Prospective study of 68 GaDOTATATE positron emission tomography/computed tomography for detecting Gastro-Entero-Pancreatic neuroendocrine tumors and unknown primary sites. J Clin Oncol 2016; 34: 588-596

[9] Gines A, Vazquez-Sequeiros E, Soria MT et al. Usefulness of EUS-guided fine needle aspiration (EUS-FNA) in the diagnosis of functioning neuroendocrine tumors. Gastrointest Endosc 2002; 56: 291- 296

[10] Jani N, Khalid A, Kaushik N et al. EUS-guided FNA diagnosis of pancreatic endocrine tumors: new trends identified. Gastrointest Endosc 2008; 67: $44-50$

[11] Chatzipantelis P, Salla C, Konstantinou P et al. Endoscopic ultrasoundguided fine-needle aspiration cytology of pancreatic neuroendocrine tumors: a study of 48 cases. Cancer 2008; 114: 255-262

[12] Pais SA, Al-Haddad M, Mohamadnejad M et al. EUS for pancreatic neuroendocrine tumors: a single-center, 11 -year experience. Gastrointest Endosc 2010; 71: 1185-1193

[13] Baker MS, Knuth JL, DeWitt J et al. Pancreatic cystic neuroendocrine tumors: preoperative diagnosis with endoscopic ultrasound and fineneedle immunocytology. J Gastrointest Surg 2008; 12: 450-456

[14] Ridtitid W, Halawi H, DeWitt JM et al. Cystic pancreatic neuroendocrine tumors: outcomes of preoperative endosonography-guided fine needle aspiration, and recurrence during long-term follow-up. Endoscopy 2015; 47: 617-625 